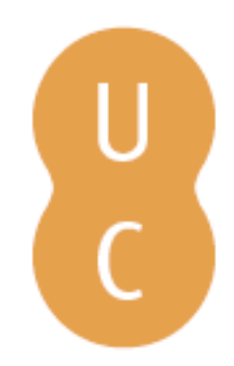

\title{
pommalina
}

\section{Medeia em seus espelhos}
Autor(es):
Anjos, Sônia Aparecida dos

Publicado por: Centro de Estudos Clássicos e Humanísticos da Universidade de

URL

persistente:

URI:http://hdl.handle.net/10316.2/30165

DOI:

DOI:http://dx.doi.org/10.14195/978-989-721-038-9_2

Accessed : $\quad$ 26-Apr-2023 10:27:28

A navegação consulta e descarregamento dos títulos inseridos nas Bibliotecas Digitais UC Digitalis, UC Pombalina e UC Impactum, pressupõem a aceitação plena e sem reservas dos Termos e Condições de Uso destas Bibliotecas Digitais, disponíveis em https://digitalis.uc.pt/pt-pt/termos.

Conforme exposto nos referidos Termos e Condições de Uso, o descarregamento de títulos de acesso restrito requer uma licença válida de autorização devendo o utilizador aceder ao(s) documento(s) a partir de um endereço de IP da instituição detentora da supramencionada licença.

Ao utilizador é apenas permitido o descarregamento para uso pessoal, pelo que o emprego do(s) título(s) descarregado(s) para outro fim, designadamente comercial, carece de autorização do respetivo autor ou editor da obra.

Na medida em que todas as obras da UC Digitalis se encontram protegidas pelo Código do Direito de Autor e Direitos Conexos e demais legislação aplicável, toda a cópia, parcial ou total, deste documento, nos casos em que é legalmente admitida, deverá conter ou fazer-se acompanhar por este aviso.

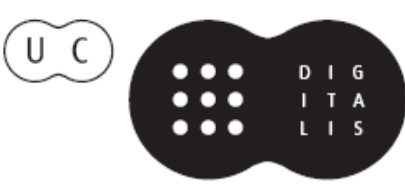




\section{De ayer a hoy}

\section{Influencias clásicas en la literatura}

\section{Aurora López, Andrés Pociña, Maria de Fátima Silva (coords.)}




\section{Medeia em seus espelhos}

Sônia Aparecida dos Anjos

Universidade de Coimbra

O objetivo dessa comunicação é analisar três personagens singulares, Medéia, Virgínia e Maria inseridas respectivamente em Medéia, de Eurípides; Anjo Negro, de Nelson Rodrigues; Medea en el espejo, de José Triana. A escolha das peças deve-se, justamente, porque as protagonistas de autores tão distantes no espaço e no tempo possuem em comum o assassinato dos próprios filhos, crime considerado terrível e monstruoso. Analisaremos, sobretudo, a adaptação do mito realizada por Eurípides, e as releituras dos dramaturgos brasileiro e cubano.

O objetivo dessa comunicação é construir uma breve análise em torno do mito de Medeia recuperado na figura de três personagens intrigantes: Medéia, Virgínia e Maria inseridas respectivamente em Medéia, de Eurípides; Anjo Negro, de Nelson Rodrigues; Medea en el espejo, de José Triana.

A escolha do título esboça a metáfora do espelho em seu sentido primordial, ou seja, o espelho nos oferece simultaneamente a imagem do real e o seu duplo. Tal percepção nos possibilita confrontos, desdobramentos e inversões; além disso, os espelhos nos apresentam um caminho para compreendermos a apropriação dos clássicos como matéria-prima para novas criações, demonstrando, assim, que a questão de como ler e adaptar os clássicos ganhou espaço nos estudos literários e culturais.

Enquanto personagem trágica Medeia é resultado da realidade social de seu tempo e das emoções que caracterizam o ser humano. A escolha das peças deve-se, em primeiro lugar, à estrutura que, temática e estruturalmente, mantém convergências com a tragédia grega e, em segundo, porque as três apresentam uma personagem singular: uma mãe que assassina a prole.

Ora, a morte dos filhos pela mãe traz em si um caráter antinatural, que consiste no fato de tanto vítima quanto agente pertencerem à mesma espécie e terem laços consanguíneos. Nesse sentido, nos apropriamos das palavras de Tereza Virgínia Ribeiro Barbosa em tratar dessas mulheres "ferozes" e "vorazes":

Neste ponto, contudo, contradizendo o senso comum, saltam furiosas à nossa mente não só as terríveis e cotidianas notícias de jornal como também todas as velhas e antigas Medeias: a de Eurípides, a de Sêneca, a de Ovídio... lançam-se como cadelas a nos morder ${ }^{1}$.

\footnotetext{
${ }^{1}$ Barbosa, Tereza Virgínia Ribeiro, "Violência na tragédia grega: infanticídios e parricídios”.
} 
Portanto, a figura de Medeia, mulher estrangeira, conceituada em magia e em outros conhecimentos serve de indagação aos sentimentos passionais contrapostos à razão humana. ${ }^{2}$ Assim, mais do que uma história de ciúme, vingança e traição extraconjugal, podemos extrair da história de Medeia um gesto que extrapola os limites da traição: a violência em sua potência, o assassinato dos filhos.

A peça de Eurípides, encenada em 431 a. C., tem início com o abandono de Medeia por Jasão. Ele trai a mulher que, em nome do amor, cometeu uma infinidade de crimes, inclusive contra os próprios familiares para protegê-lo. De tal modo, ela e Jasão foram perseguidos até se refugiarem em Corinto, na corte do rei Creonte. Teriam vivido em paz, mas o rei resolveu casar sua filha com o herói da Tessália. Por ambição e interesse, pensando na linhagem nobre dos futuros filhos, Jasão cede à tentação de desposar a filha do rei ${ }^{3}$.

Vítima de um ultraje, maldizendo sua biologia, Medeia afirma preferir mil vezes o escudo que dar a luz uma só vez. ${ }^{4}$ Debulhada em lágrimas, de face voltada para o chão e entregue ao sofrimento, ela evidencia as características psicológicas mais profundas da alma humana, mas ela precisa encontrar forças para promover a reviravolta.

Ela lança para os filhos um olhar de touro, como se estivesse prestes a fazer algo terrível ${ }^{5}$. Seu gesto oscila entre a ternura e horror, não obstante o ódio e o desejo de vingança são mais fortes do que qualquer outro sentimento. Assim, do texto de Eurípides, selecionamos o relato de Medeia denunciando a difícil tarefa que deveria empreender. Matar os filhos que lhe eram tão caros.

Medéia: Amigas, decidida está minha ação: matar os filhos o mais depressa possível que puder e evadir-me desta terra, não vá acontecer que, ficando eu ociosa, abandone as crianças, para serem mortas por mão mais hostil. É absoluta a necessidade de as matar, e já que é forçoso, matá-la-emos nós, nós que as geramos. Mas vamos, arma-te coração! Porque hesitamos e não executamos os males terríveis, mas necessários? (Erguendo a mão) Anda, ó minha mão, empunha a espada, move-te para a meta dolorosa da vida, não te deixes dominar pela covardia, nem pela lembrança dos teus filhos, de como eles te são caros, de como os geraste. vv. 1236-1246. (...)

Jasão: Eu vim para salvar a vida dos meus filhos, não vão os parentes fazer-lhes alguma coisa para vingar o crime materno.v. 1306 (...)

In.: Nuntius Antiquus. Belo Horizonte, no 5, julho de 2010, p. 132.

2 Cancela, Elina Miranda. "Medea y la voz del otro en el teatro Latino-americano contemporáneo”. Revista La Ventana, no 22/2005, pp. 70-72.

${ }^{3}$ Tradução de Maria Helena da Rocha Pereira.

${ }^{4}$ Cf. Eurípides, Medeia, v. 250-251.

${ }^{5}$ Romilly, Jaqueline, A tragédia grega. Lisboa, Edições 70, 1997.p. 111. 
Coro: Teus filhos estão mortos pela mão de sua mãe. v. 1309. (...) Jasão: Que me concedas dar sepultura a estes cadáveres e chora-los.

Medéia: Isso não, que eu mesma com minhas mãos lhes darei sepultura... vv. 1377-1378.

O coro repudia a atitude de Medeia. Porém, se o crime da feiticeira é resultado de sua ilimitada paixão, o erro de Jasão decorre de seu egoísmo também ilimitado. Quando Jasão recebe a notícia da morte dos filhos entra em desespero, não lhe é concedido o direito de uma última carícia nos filhos e tão pouco o direito de dar-lhes sepultura e chorar sobre os cadáveres. Medeia os sepultará sozinha, fugindo de Corinto no carro do Sol (deus ex machina).

Dramaturgo inquieto, Nelson Rodrigues tinha predileção por personagens que se consideram acima do bem e do mal e que por isso se colocam no plano mítico. Tem-se, então, no plano religioso ou moral protagonistas sórdidos, ensandecidos, monstros que praticavam crimes hediondos sem serem julgados ou punidos ${ }^{6}$; no plano humano, seres divididos, complexos, assolapados em suas bases familiares pelas muitas contingências da vida.

Desta forma, a renovação da dramaturgia brasileira por Nelson Rodrigues se dá através de um retorno a uma tradição mitológica primordialmente registrada na tragédia grega, uma das matrizes do teatro ocidental ${ }^{7}$.

Em Anjo Negro, de 1948, a ação se desenvolve na intimidade do lar. ${ }^{8}$ A ausência de teto desvela uma noite incessante que paira sobre a casa ${ }^{9}$ e que amplia o cosmo teatral, recuperando o espaço aberto do teatro grego, ainda que de forma ficcional. As paredes crescem de um ato para outro, acentuando a atmosfera angustiante, o cenário se configura numa fortaleza inexpugnável, onde as leis da sociedade não podem atingi-la.

Para não deixar dúvidas em relação ao espaço cênico como uma projeção da mente atormentada dos protagonistas, Rodrigues criou uma rubrica poética: "a casa não tem teto para que a noite possa entrar e possuir os moradores. Ao fundo, grandes muros que crescem à medida que aumenta a solidão do negro" ${ }^{10}$.

A peça tem seu início no velório de uma criança, o terceiro filho do casal. $\mathrm{Na}$ cerimônia fúnebre, está presente um coro de mulheres que lamenta a terceira morte consecutiva dos filhos daquela casa. O coro modernizado, formado por dez pretas idosas e descalças, funciona como na tragédia grega, servindo para mostrar ao espectador a opinião de alguém que está fora da trama ${ }^{11}$.

${ }^{6}$ Fraga, Eudinyr, Nelson Rodrigues Expressionista. São Paulo, Ateliê Editorial, 1998, p. 89-91.

${ }^{7}$ Legangneux, Patrícia, Les tragédies grecques sur la scène moderne: Une utopie théâtrale, Louvain, Presses Universitaires Septentrión, 2004, p. 18.

${ }^{8}$ Rodrigues, Nelson, Anjo Negro, Rio de Janeiro, Nova Fronteira, 2005, p. 7.

${ }^{9}$ Facina, Adriana, Santos e Canalhas, Rio de Janeiro, Civilização Brasileira, 2004, p. 111.

${ }^{10}$ Fraga, Eudinyr, Nelson Rodrigues Expressionista, 1998, pp. 89-91.

${ }^{11}$ Rodrigues, Nelson, Anjo Negro, 2005, pp. 7-23. 
As negras comentam que Virgínia não amava o filho porque ele nasceu com a cor do pai; que ela não chorou nenhuma lágrima; que os outros dois filhos do casal morreram com a mesma idade, em circunstâncias igualmente suspeitas. Aparece-nos, portanto, uma questão inevitável: por que estas crianças morrem tão misteriosamente?

A motivação do infanticídio desvela outro crime: o estupro de Virgínia por Ismael. Os filhos negros são a lembrança "viva" dessa violência ${ }^{12}$. A marca do estupro se inscreve no corpo de Virgínia, principalmente na geração de filhos pretos, reflexos do pai.

Ismael: (...) Por que odiaste meus filhos?

Virgínia: (recuando) Não odiei teus filhos.

Ismael: Odiaste. Antes deles nascerem, quando estavam ainda no seu ventre tu já os odiava. Porque eram meus filhos... os odiava. Porque eram meus filhos... (...) E porque eram pretos e se pareciam comigo. Tu mesma disseste - que tinham o meu rosto...

Virgínia: (olhando a fisionomia do marido) Tinham o teu rosto...

Ismael: Eles morreram porque eram pretos...

Virgínia: (com terror) Foi o destino.

Ismael: (contendo-se ainda) Porque eram pretos. (novo tom) Pensas que eu não sei? Virgínia: (recuando, num sopro de voz) Não, Ismael, não!...

Ismael: Que fizeste com meus filhos?

Virgínia: (apavorada) Nada - não fiz nada...

Ismael: Mataste (baixa a voz). Assassinaste. (com violência contida) Não foi o destino: foste tu, foram tuas mãos, estas mãos... (...) Um por um. Este último, o de hoje, tu mesma o levaste, pela mão. Não lhe disseste uma palavra dura, não o assustaste; nunca foste tão doce. Junto do tanque, ainda o beijaste; depois, olhaste em torno. Não me viste, lá em cima, te espiando... Então, rápida e prática - já tinhas matado dois -, tapaste a boca do meu filho, para que ele não gritasse... Só fugiste quando ele não mexia mais no fundo do tanque...

Virgínia: (feroz, acusadora) Então, porque não gritou? Por que não impediu? (...)

Ismael: Não impedi porque teus crimes nos uniam ainda mais; e porque meu desejo é mais depois que te sei assassina - três vezes assassina. Ouviste? (com uma dor maior) Assassina na carne dos meus filhos...

Virgínia: (selvagem) Eu queria livrar minha casa de meninos pretos. Destruir, um por um, até o último. Não queria acariciar um filho preto... ${ }^{13}$.

Ela confessa a negação contra o marido, impedindo que este perpetue sua descendência, pois não quer ver nos filhos a cor e, por conseguinte, o homem

\footnotetext{
${ }^{12}$ Rodrigues, Nelson, Anjo Negro, 2005, pp. 30-35.

${ }^{13}$ Rodrigues, Nelson. Anjo Negro, 2005, pp. 51-53.
} 
que ela rejeitara. Porém, diferentemente das personagens masculinas das outras peças, Jasão e Julián, Ismael é cúmplice do infanticídio. Essa cumplicidade representa metaforicamente o crescimento do desejo do suicídio por Ismael. ${ }^{14}$ Ismael não quer transmitir a sua "cor" a outras gerações. Como ele mesmo não se aceitava, consentia que a esposa matasse uma parte de si.

Ismael tentava se esquecer de tudo que pudesse lembrá-lo de sua afrodescendência, afastando-se de qualquer comportamento que o aproximasse da cultura negra: não ingeria bebida alcóolica, não jogava ou frequentava ambientes suspeitos de malandragem. Ele assimilou os "bons costumes" da elite branca ${ }^{15}$, e desejava se aproximar, no plano aparente, ao branco (nariz afilado, cabelos lisos, lábios finos, cútis clara) ${ }^{16}$, de maneira que a negação de sua ancestralidade pode ser compreendida como uma fuga étnica. ${ }^{17}$ Ainda vivíamos os vestígios da propagação eugenista e a política do branqueamento da nação. De forma que racismo no Brasil manifestava-se pelo branqueamento (físico e psicológico) dos indivíduos bem sucedidos e o enegrecimento ou empardecimento dos fracassados ${ }^{18}$.

Redimensionando nossa pesquisa em torno da violência materna em outro espaço e tempo, apresentamos Medea en el espejo, do dramaturgo cubano José Triana. Triana despontou nos primeiros anos da Revolução Cubana através da fundação do Teatro Nacional. Sua obra em estudo foi levada ao palco em 1960, em pleno triunfo da Revolução ${ }^{19}$ e aborda a cultura, os costumes e os ritos afro-cubanos ${ }^{20}$.

O nome Medeia, por exemplo, aparece no título acompanhado por um elemento dos rituais afro-cubanos utilizado para encontrar uma pessoa desaparecida: o espelho, que também possuía a função de oráculo. ${ }^{21} \mathrm{O}$ uso do espelho obriga Maria a se reconhecer como mulata ao mirar-se nele. A cor da pele, nesse sentido, aparece como estigma, pois Maria transmite informações sobre sua identidade social mesmo contra a própria vontade ${ }^{22}$.

${ }^{14}$ Magaldi, Sábato, Teatro da Obsessão, São Paulo, Global, 2004, p. 60.

${ }^{15}$ Rodrigues, Nelson. Anjo Negro, 2005, pp. 28-29.

${ }^{16}$ Facina, Adriana, Santos e Canalhas, 2004, p. 112.

${ }^{17}$ Martins, Leda Maria, A Cena em Sombras, São Paulo, Perspectiva, 1995, p. 164.

${ }^{18}$ Schwarcz, Lilia Moritz, "Nem preto, nem branco, muito pelo contrário: cor e raça na intimidade". In: Novais, Fernando, História da Vida Privada no Brasil, Vol. IV, São Paulo, Cia das letras, 1998, p. 182.

${ }_{19}$ Miranda Cancela, Elina, "Medea y la voz del otro en el teatro Latino-americano contemporáneo", 2005, p. 73.

${ }^{20}$ Fernández, Carolina Ramos, "Redescubriendo a los mitos griegos desde el continente americano: la Medea mulata de José Triana", The Hebrew University of Jerusalem, Vol. 2, no 1 , Feb/2009, p. 126.

${ }^{21}$ Croguennec-Massol, Gabrielle, "Marginalisation et identité dans Medea en el espejo, de José Triana”, Université Paris-Sorbonne Paris IV, p. 2.

${ }_{22}$ Croguennec-Massol, Gabrielle. "Marginalisation et identité dans Medea en el espejo, de José Triana”, p. 4. 
A grande preciosidade dessa peça encontra-se na abundância de didascálias responsáveis pela caracterização física e psicológica das personagens, bem como aos seus movimentos ${ }^{23}$. O espaço cênico é um solar indicando unidade de espaço. ${ }^{24} \mathrm{~A}$ peça, dividida em três atos, apresenta unidade temporal, começando ao entardecer, atravessando as primeiras sombras da noite até o raiar da aurora. A linguagem vale-se, sobretudo, de expressões de origem iorubá comuns entre as classes sociais mais baixas.

Maria é uma mulata, amante de um branco, que reside no solar compartilhando a vida com outras pessoas igualmente pobres. Submissa ao amante, Julián, ela não aceita e nem conhece outro destino ${ }^{25}$. Porém, enfrenta a grande reviravolta de sua vida ao descobrir que seu amado se casará com outra: uma moça branca, filha do dono do solar onde ela vive: Pierico Piedra Fina ${ }^{26}$. Ao descobrir as intenções de Julián, ${ }^{27}$ Maria decide vingar-se. Ela assassina o futuro sogro e a esposa do ex-amante, envenenando-os ${ }^{28}$.

O aparecimento de dois velhos negros, Madame Pitonisa e o Doutor Mandinga ${ }^{29}$, traz para o palco os ritos da religiosidade afro-cubana. Através da intervenção dos "bruxos", Maria entra em transe, uma forma de mediação direta com os ancestrais ${ }^{30}$.

Os "bruxos" a aconselham a buscar pela luz, possível apenas se ela eliminar Julián de sua vida ${ }^{31}$. Porém, basta ela olhar para os filhos e ver neles o reflexo do amante. Ela não se vê refletida neles, portanto, eliminar o amante é insuficiente, é preciso acabar com o elo máximo entre os dois: os filhos.

María:(...) Es necesario que me levante contra esa María que me arrastra y me humilla. (Se levanta.) (...)Yo soy la otra, la que está en el espejo (...).(Enérgica.) (...) Ahora no tengo miedo. (...) Ahora sé qué soy (Breve riso histérico.) Que soy, que ya no existen ataduras, ni temores, ni humillaciones, porque sólo sabiendo, yo soy yo; que ya no me importan ni el bien ni el mal, que toda esa patraña la he

${ }^{23}$ Ferreira, Luísa de Nazaré, "A permanência do trágico em Medeia ao Espelho, de José Triana", Boletim de Estudos Clássicos, Universidade de Coimbra, Vol. 33, 2000 (Junho), p. 127.

${ }^{24}$ Fernández, Carolina Ramos, "Redescubriendo a los mitos griegos desde el continente americano: la Medea mulata de José Triana”,2009, p.127. Cf.: Prandi, Reginaldo, "O candomblé e o tempo", Revista Brasileira de Ciências Sociais, vol. 16, n. 47, outubro/2001, p. 45.

${ }_{25}$ Miranda Cancela, Elina, "Medea y la voz del otro en el teatro Latino-americano contemporáneo", 2005, p. 74.

${ }^{26}$ Croguennec-Massol, Gabrielle, "Marginalisation et identité dans Medea en el espejo, de José Triana", p. 4.

${ }^{27}$ Triana, José, Medea en el espejo, 1960, p. 108.

${ }^{28}$ Triana, José, Medea en el espejo, 1960, pp. 111-112.

${ }^{29}$ Fernández, Carolina Ramos, "Redescubriendo a los mitos griegos desde el continente americano: la Medea mulata de José Triana”, 2009, pp. 129-130.

${ }^{30}$ Croguennec-Massol, Gabrielle. "Marginalisation et identité dans Medea en el espejo, de José Triana”, p. 4.

${ }^{31}$ Triana, José, Medea en el espejo, 1960, p. 118. 
borrado; ahora soy; que tus brazos, Julián, que tu cuerpo, Julián, son una triste historia; yo que he estado aferrándome a un fantasma, que necesito la vida, sí, la vida: en el horror; en la sangre, en la ternura, en la indiferencia, en el crimen. Sé que necesito la vida, que este cuerpo me empuja hacia la vida, que antes estaba muerta y que ahora soy María, soy yo. (Pausa. Repentinamente ausente.) ¿Dónde están mis hijos? (En un grito.) Erundina. (Pausa. Otro grito.) Señorita Amparo. (Pausa.) ¿Dónde se han metido? (Pausa. Con odio, pero tranquila.) Me vengaré Julián. No podrás detenerme. (...)(Gritando.) Mis hijos. ¿Dónde están mis hijos? (Pausa. Otro tono.) Ahora no es el amor; o quizás, sí; un amor que va más allá de ti y de mí y de las palabras; un amor que exige el sacrificio y el odio; un amor que lo destruye todo para siempre empezar de nuevo. (Pausa larga.) Silencio. Ahí están mis hijos. Que nadie los despierte. Julián ha muerto y ellos seguirán dormidos para siempre. (Hace gesto de silencio.) Mi vida empieza, Julián. Mi vida empieza, hijos míos. María se ha encontrado. (Como si viera aparecer multitud de espejos en el escenario.) Un espejo, ahí. Un espejo, allí. Otro espejo, aquí. Estoy rodeada de espejos y yo también soy un espejo ${ }^{32}$.

Ela deseja aniquilar todas as lembranças de sua vida anterior e se reconhece enquanto corpo, vida e vontade ${ }^{33}$. O espelho também lhe revela uma mulher que carregava nos ombros séculos de estereótipos étnicos negativos. Maria renasce a partir dos inúmeros espelhos que a cercam e a constituem em sua magnitude assassina ${ }^{34}$.

A solução final do conflito de Triana possui inegável relação com a peça de Eurípides. Maria, após o infanticídio, está completamente fora de si se autointitulando a deusa da vingança. O coro, chamando-a de assassina ao som dos tambores, a carrega como um troféu a exemplo do deus ex machina.

Triana critica a sociedade cubana da época, uma sociedade profundamente dividida e estruturada, deixando as áreas menos favoráveis aos que não pertencem a raça branca ${ }^{35}$. Em sua potência máxima, Maria faz renascer uma Medeia para além do ódio e do ciúme, capaz de recuperar suas raízes africanas atrofiadas pelo preconceito de uma sociedade elitista. Em seu movimento espiralar, Maria submerge de sua invisibilidade e se torna uma alegoria de Cuba que renascia após o movimento revolucionário.

${ }^{32}$ Triana, José, Medea en el espejo, 1960, pp.119-121.

${ }^{33}$ Triana, José, Medea en el espejo, 1960, p.118.

${ }^{34}$ Triana, José, Medea en el espejo, 1960, pp.119-121.

35 Fernández, Carolina Ramos, "Redescubriendo a los mitos griegos desde el continente americano: La Medea mulata de José Triana”, 2009, p. 140. 


\section{Bibliografía}

Barbosa, Tereza Virgínia Ribeiro, "Violência na tragédia grega: infanticídios e parricídios”, In: Nuntius Antiquus. Belo Horizonte, no 5, julho de 2010, pp. 141-152.

Croguennec-Massol, Gabrielle, "Marginalisation et identité dans Medea en el espejo de José Triana". In: Université Paris-Sorbonne Paris IV.

Facina, Adriana, Santos e Canalhas, Rio de Janeiro, Civilização Brasileira, 2004.

Fernández, Carolina Ramos, "Redescubriendo a los mitos griegos desde al continente americano: la Medea mulata de Jose Triana", In: The Hebrew University of Jerusalem - vol. 2. no 1. Feb-2009, pp. 126-141.

Ferreira, Luísa de Nazaré, "A permanência do trágico em Medeia ao Espelho, de José Triana", Boletim de Estudos Clássicos, Universidade de Coimbra, Vol. 33, 2000 (Junho), pp. 124-135.

Fraga, Eudinyr, Nelson Rodrigues Expressionista, São Paulo, Ateliê Editorial, 1998.

Legangneux, Patrícia, Les tragédies grecques sur la scène moderne: Une utopie théâtrale, Louvain, Presses Universitaires Septentrión, 2004, p. 18.

Magaldi, Sábato, Teatro da Obsessão, São Paulo, Global, 2004.

Martins, Leda Maria, A Cena em Sombras, São Paulo, Perspectiva, 1995.

Miranda Cancela, María Elina, "Mito y mujeres en el teatro cubano actual", In: Favaretto, Silvia, Narrative e femminili cubane: mito e realtá, Venezia, 2003. pp. 53-73.

,"Medea yla voz del otro en el teatro Latino-americano contemporáneo", Revista La Ventana, no 22/2005, pp. 69-90.

___ ,Entre cubanos: del cara al mundo clasico", Revista Opus Habana, pp. $17-25, \mathrm{~s} / \mathrm{d}$.

___ "Palinodia de Medea en el teatro cubano actual", Universidad de La Habana, pp. 289-296.

Rodrigues, Nelson, Anjo Negro, Rio de Janeiro, Nova Fronteira, 2005.

Romilly, Jaqueline, A tragédia grega, Lisboa, Edições 70, 1997.

Schwarcz, Lilia Moritz, "Nem preto, nem branco, muito pelo contrário: cor e raça na intimidade", In: Novais, Fernando, História da Vida Privada no Brasil, Vol. IV, São Paulo, Cia das letras, 1998.

Triana, José, Medea en el espejo, 1960. 